\title{
XIII. On two new salts of chromic acid
}

\section{Archibald Duncan Jun. Esq.}

To cite this article: Archibald Duncan Jun. Esq. (1850) XIII. On two new salts of chromic acid, Philosophical Magazine Series 3, 36:241, 109-110, DOI: 10.1080/14786445008646436

To link to this article: http://dx.doi.org/10.1080/14786445008646436

$$
\text { 册 Published online: } 30 \text { Apr } 2009 .
$$

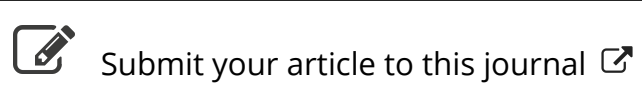

\footnotetext{
Џ Article views: 2
}

Q View related articles $\sqsubset$ 


\section{On two New Salts of Chromic Acid. By Archibald Duncan, Jun., Esq.*}

N 1827, Dr. Thomson described in his paper on the Com1 pounds of Chromium (Phil. Trans. 1827, p. 223), the double salt-potash chromate of magnesia- $\left(\mathrm{KO} \mathrm{CrO}_{3}, \mathrm{MgO}\right.$ $\mathrm{CrO}_{3}, 2 \mathrm{HO}$ ) obtained by digesting a solution of bichromate of potash over carbonate of magnesia. I obtained a corresponding lime-salt about two years ago by the following process. A boiling solution of bichromate of potash was poured over newly-slaked lime in a tall vessel. The undissolved lime having subsided, the supernatant fluid, which was of a lemon-yellow colour, was drawn off by a syphon, and slowly evaporated in a hot-air stove at $80^{\circ}$. During the first two days of the evaporation, crystalline crusts of an orange salt were formed on the surface of the liquor, and required to be frequently removed. After this time, however, these crusts ceased to be produced, and crystals of a yellow salt began to make their appearance at the bottom of the evaporating bason, and in two or three days more a mass of beautiful crystals was obtained. The proportion of the orange to the yellow salt depends a good deal on the temperature employed in the evaporation. In one experiment the heat was raised to boiling, and no yellow crystals were obtained at all, orange crusts continuing to separate as fast as they could be removed.

Yellow Potash Chromate of Lime.-This salt crystallizes in lemon-yellow four-sided oblique prisms. It is soluble in water, but insoluble in cold alcohol, and is formed in the latter part of the process described.

The salt, when ignited, fuses; and on cooling, the mass has a crystalline aspect, and is quite soluble in water.

The mean of several analyses gave the following result:-

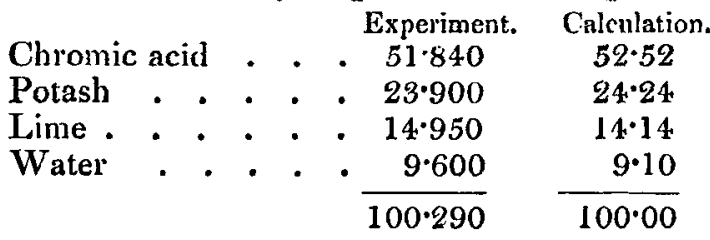

This corresponds nearly with the formula $\mathrm{KO} \mathrm{CrO}_{3}, \mathrm{CaO}$ $\mathrm{CrO}_{3}+2 \mathrm{HO}$, the water being slightly in excess. It therefore is a parallel compound to the magnesian salt described by Dr. Thomson.

Orange Potash Chromate of Lime.-The mode of formation

* Communicated by the Anthor, having been read before the Philosophical Society of Glasgow, Dec. 13, 1848. 
of this salt has been already described. It is soluble in water. The mean of three analyses yielded the following result:-

\begin{tabular}{|c|c|c|c|c|}
\hline \multicolumn{5}{|c|}{ Chromic acid } \\
\hline Lime. & & - & - & $23 \cdot 990$ \\
\hline Potash & & - & - & $17 \cdot 550$ \\
\hline & . & . & . & 6.230 \\
\hline
\end{tabular}

This approaches nearly to the formula $3 \mathrm{KO} 7 \mathrm{CaO} \mathrm{CrO}_{3}$ $5 \mathrm{HO}$. When this salt is ignited it does not fuse, and when cool its colour is yellow. It does not again altogether dissolve in water, and thence it appears to have undergone decomposition.

XIV. Remarks on the Weather during the Quarter ending December 31, 1849. By James Graisher, Esq., F.R.S., F.R.A.S., and of the Royal Observatory, Greenwich*.

T $N$ my paper upon the meteorological particulars of the 1 quarter ending September 30, 1849, and published in the Philosophical Magazine, I spoke of the great mortality which had existed throughout that quarter in London and its environs. This excess of mortality decreased rapidly; and not less remarkable has been the decrease in the weekly and monthly rate of mortality in the past quarter; the mortality having been, in three successive weeks in November, 269, 284, and 270 below the estimated number. The mortality in October was 557, in November was 1160, and in December was 564 less than the calculated numbers. This decrease is extraordinary: and it proves that the epidemic of cholera carried off many of the sickly and weakly, whose deaths would otherwise have made up the average numbers in the past quarter.

The meteorological returns for the past quarter have been furnished to the Registrar-General from the usual places, and which have passed my usual examination and reduction.

During the past quarter there has been an unusual prevalence of fog, particularly in the month of November. Snow has fallen more frequently than usual, but in small quantities only. The daily temperatures of the air till October 16 and after November 20, with the under-mentioned exceptions, were below their average values; in the former period the mean defect was $4^{\circ} \cdot 2$, and in the latter it was $4^{\circ} \cdot 0$. Between October 17 and November 14 the temperature was above the

* Communicated by the Author. 